\title{
Metabolite concentrations in follicular fluid may explain differences in fertility between heifers and lactating cows
}

\author{
K Bender $^{1,2}$, S Walsh ${ }^{1}$, A C O Evans ${ }^{1,2}$, T Fair ${ }^{1}$ and L Brennan ${ }^{1,2}$ \\ ${ }^{1}$ UCD School of Agriculture, Food and Veterinary Medicine and ${ }^{2}$ UCD Conway Institute, University College Dublin, \\ Belfield, Dublin 4, Ireland
}

Correspondence should be addressed to L Brennan at UCD School of Agriculture, Food and Veterinary Medicine, UCD Conway Institute, University College Dublin; Email: lorraine.brennan@ucd.ie

\begin{abstract}
There has been a marked decline in the fertility of dairy cows over the past decades, and metabolomic analysis offers a potential to investigate the underlying causes. Metabolite composition of the follicular fluid, which presents the intrafollicular environment, may be an important factor affecting oocyte maturation and subsequent early embryo development. The aim of the present study was to investigate the metabolic differences between follicular fluid from the dominant follicle of lactating cows and heifers using gas chromatography mass spectrometry (GC-MS)-based metabolomics. Follicular fluid and serum were collected from cows and heifers over three phases of follicle development: newly selected dominant follicles, preovulatory follicles prior to oestrus and post-LH surge follicles. Analysis of the fatty acids revealed that there were 24 fatty acids and 9 aqueous metabolites significantly different between cows and heifers. Of particular interest were the higher concentrations of saturated fatty acids (palmitic acid, $P=0.001 ;$ stearic acid, $P=0.005$ ) in follicular fluid from cows and higher docosahexaenoic acid levels $(P=0.022)$ in follicular fluid from heifers. Analysis of the metabolite composition of serum revealed that follicular fluid had a unique lipid composition. The higher concentrations of detrimental saturated fatty in cows will have a negative impact on oocyte maturation and early embryo development. Overall, the results suggest that the follicle microenvironment in cows potentially places their oocytes at a developmental disadvantage compared with heifers, and that this may contribute to well-characterised differences in fertility.

Reproduction (2010) 139 1047-1055
\end{abstract}

\section{Introduction}

A large body of evidence exists to show a decline in fertility in high-yielding dairy cows over the last two decades (Foote 1996, Butler 2000, Lopez-Gatius 2002). Many studies have investigated and continue to investigate the physiology and pathogenesis behind this reduced fertility, and a multifactorial picture is emerging. Recently, the importance of oocyte and embryo quality in the final fertility outcome has been highlighted (Vanholder et al. 2005, Sirard et al. 2006). It has been postulated that the follicular fluid which provides the oocyte microenvironment is at least partly responsible for subsequent embryo quality and development (McNatty 1978). Follicular fluid provides the oocyte with protection against proteolysis and extrusion during ovulation (Espey \& Lipner 1994), and acts as a buffer against adverse haematic influences (Gosden et al. 1988). Follicular fluid is a product of both the transfer of blood plasma constituents that cross the blood follicular barrier and of the secretory activity of granulosa and thecal cells (Gosden et al. 1988,
Fortune 1994). It has been proposed and subsequently shown in postpartum cows that due to the close correlation between follicular fluid and serum levels of certain metabolites, metabolic changes in serum concentrations will be reflected in the follicular fluid and therefore may affect the quality of both the oocyte and the granulosa cells (Leroy et al. 2004a, 2004b). More recent studies have shown that the fatty acid composition of follicular fluid from dairy cows is different from that of plasma, and that it is dependent on oestrogen activity (Renaville et al. 2008).

Several studies have taken a novel approach towards the assessment of oocyte quality by characterising specific classes of metabolites, such as fatty acids (Zeron et al. 2001, Leroy et al. 2005), amino acids (Booth et al. 2005) and carbohydrates (Preis et al. 2005). The latter study also demonstrated that oocytes that are able to absorb large amounts of glucose and actively convert it into lactate have the highest fertilisation potential. It has been reported that, in cows, follicular fluid nutrient levels fluctuate according to the follicle dominance and stage of the oestrus cycle; most amino 
acid concentrations in the dominant follicular fluid are affected by the stage of oestrous cycle; however, pyruvate and glucose concentrations were shown to be unaffected by follicle dominance (Orsi et al. 2005). These results suggest that subordinate follicles undergo very different metabolic processes from dominant follicles. Additionally, another study reported higher concentrations of linoleic acid and lower concentrations of non-esterified fatty acids (NEFA), oleic acid and arachidonic acid in dominant follicles, whereas subordinate follicles had NEFA levels closer to plasma concentrations (Renaville et al. 2008).

Recent studies have highlighted the potential of metabolomic strategies in the assessment of embryo and oocyte quality (Singh \& Sinclair 2007, Sinclair et al. 2008, Revelli et al. 2009). Metabolomics is defined as the characterisation of the small-molecule metabolites found in an organism or biological sample. Low-molecular weight metabolites represent the intermediates or end products of the cell's regulatory processes, and their individual profile is also referred to as a 'metabolic fingerprint' (Kell 2005). Since the metabolome is interlinked to an organism's genotype, physiology and environment, it provides a powerful tool to assess the physiological state and to assist in the identification of possible biomarkers for fertility research (Baka \& Malamitsi-Puchner 2006, Sinclair et al. 2008). Despite the significant potential of metabolomic analysis of follicular fluid to predict oocyte developmental competence and subsequent embryo quality, over classical morphological examination (Revelli et al. 2009), comprehensive metabolic profiling of follicular fluid is limited.

Initial approaches in metabolic profiling of bovine follicular fluid indicate a relationship between bovine follicular L-alanine and glycine concentrations and oocyte cleavage following IVF (Sinclair et al. 2008). Similarly, intrafollicular L-arginine and L-alanine amino acid concentrations were reportedly associated with blastocyst formation, and therefore, are potential predictors of oocyte quality in pigs (Hong \& Lee 2007). This is quite interesting, as it has been shown that bovine IVF embryos have an early requirement for L-arginine, L-glutamine and glycine ( $\mathrm{Li}$ et al. 2006). Overall, these studies suggest a potential useful role for metabolomic analysis in fertility-related research.

In the present study, we performed metabolic profiling of follicular fluid of the dominant preovulatory follicle at different stages of follicle differentiation from a group of dairy cows and heifers representing a low- and highfertility model respectively. In addition, serum samples and follicular fluid from the subordinate follicles were also analysed. Overall, the results give an insight into the composition of follicular fluid and its potential impact on oocyte development.

\section{Results}

\section{Analysis of follicular fluid of dominant preovulatory follicles from cows and heifers}

\section{Fatty acids}

A total of 37 fatty acids were identified in the follicular fluid. Of these, it was possible to quantify 25 and semi-quantify 12 (Table 1 ). In cows, the fatty acid with the highest concentration was linoleic acid, followed by oleic acid, stearic acid and palmitic acid. In heifers, the same four fatty acids were also highest in abundance; however, their ranking was different, with oleic acid being the highest followed by linoleic acid, stearic acid and palmitic acid.

Principal component analysis (PCA) of the fatty acid data revealed that there were significant differences in the fatty acid composition of follicular fluid from cows and heifers. For quantified compounds, the first three principal components explained $99.2 \%$ of the variation in the data (see Fig. 1). Analysis of the corresponding loadings revealed that there was an increased level of oleic acid, palmitic acid, stearic acid, linoleic acid and linolenic acid in the follicular fluid from cows. Further analysis, using a general linear model, showed that only one compound ( $\gamma$-linolenic acid) was significantly different between the groups. However, post hoc Bonferroni's analysis revealed that the group differences were not significant. Moreover, only one compound (erucic acid) had a significant group $\times$ animal interaction. As a result, the remaining analysis focused on animal effects in the follicular fluid. The general linear model analysis revealed that 23 compounds were significantly different. Table 1 summarises the changes for the quantified compounds, and those for the semiquantified compounds are given in the Supplementary Tables 1 and 2, see section on supplementary data given at the end of this article. Additionally, saturated fatty acid (SFA), polyunsaturated fatty acid (PUFA), monosaturated fatty acid (MUFA), (n-3)PUFA and (n-6)PUFA were all significantly higher in follicular fluid from cows (Table 1). Furthermore, indices of desaturase enzyme activity in C16 fatty acids $\left(\Delta^{9}\right.$-desaturase (16)) and in C18 fatty acids $\left(\Delta^{9}\right.$-desaturase (18)) were significantly higher in follicular fluid from cows. The index of elongase enzyme activity in the chain lengthening of C16-C18 was significantly higher in cows than in heifers.

\section{Aqueous metabolites}

A total of 52 aqueous compounds were identified, of which, 20 were quantified and 32 were semi-quantified. PCA showed no separation of follicular fluid profiles from cows and heifers. Further analysis using a general linear model revealed that a small number of metabolites (9) were significantly different between cows and heifers, and that eight metabolites had significant group effects. However, only one metabolite (L-oxoproline) had a 
Table 1 Fatty acid composition of the follicular fluid from preovulatory dominant follicles from cows $(n=10)$ and heifers $(n=11)$. Values are expressed as means $(\mu \mathrm{g} / \mathrm{ml}) \pm$ s.E.M.

\begin{tabular}{|c|c|c|c|}
\hline Fatty acid & Cow & Heifer & $\boldsymbol{P}$ \\
\hline Myristoleic acid (C14:1) & $0.085 \pm 0.017$ & $0.037 \pm 0.010$ & NS \\
\hline Myristic acid (C14:0) & $1.746 \pm 0.170$ & $0.896 \pm 0.062$ & 0.001 \\
\hline Pentadecenoic acid (C15:1) & $0.086 \pm 0.054$ & $0.124 \pm 0.068$ & NS \\
\hline Palmitoleic acid (C16:1) & $8.994 \pm 0.933$ & $2.794 \pm 0.402$ & $<0.001$ \\
\hline Palmitic acid (C16:0) & $45.495 \pm 3.227$ & $26.290 \pm 2.491$ & 0.001 \\
\hline Heptadecenoic acid (C17:1) & $2.649 \pm 0.245$ & $2.085 \pm 0.177$ & NS \\
\hline$\gamma$-Linolenic acid (C18:3n6) & $2.242 \pm 0.293$ & $0.976 \pm 0.123$ & $<0.001$ \\
\hline Linoleic acid (C18:2n6) & $219.399 \pm 20.718$ & $47.782 \pm 7.290$ & $<0.001$ \\
\hline Linolenic acid (C18:3n3) & $29.836 \pm 2.971$ & $14.823 \pm 1.549$ & 0.002 \\
\hline Oleic acid (C18:1n9c) & $209.473 \pm 15.255$ & $86.830 \pm 10.661$ & $<0.001$ \\
\hline Stearic acid (C18:0) & $54.286 \pm 4.976$ & $31.345 \pm 3.243$ & 0.005 \\
\hline Arachidonic acid (C20:4n6) & $7.981 \pm 0.601$ & $8.905 \pm 1.032$ & NS \\
\hline EPA (C20:5n3) & $10.351 \pm 0.594$ & $10.983 \pm 1.151$ & NS \\
\hline DGLA (C20:3n6) & $4.641 \pm 0.344$ & $2.841 \pm 0.299$ & 0.001 \\
\hline cis-Eicosadienoic acid (C20:2) & $0.210 \pm 0.048$ & $0.078 \pm 0.034$ & 0.036 \\
\hline cis-11-Eicosanoic acid (C20:1) & $0.156 \pm 0.041$ & $0.066 \pm 0.028$ & 0.031 \\
\hline ETE (C20:3n3) & $0.013 \pm 0.003$ & $0.022 \pm 0.006$ & NS \\
\hline Arachidic acid (C20:0) & $0.127 \pm 0.011$ & $0.101 \pm 0.018$ & NS \\
\hline Heneicosanoic acid (C21:0) & $0.015 \pm 0.004$ & $0.009 \pm 0.001$ & NS \\
\hline DHA (C22:6n3) & $0.431 \pm 0.073$ & $1.024 \pm 0.199$ & 0.022 \\
\hline Erucic acid $(C 22: 1 n 9)^{a}$ & $0.070 \pm 0.017$ & $0.033 \pm 0.009$ & 0.003 \\
\hline Behenic acid (C22:0) & $0.234 \pm 0.049$ & $0.101 \pm 0.032$ & 0.047 \\
\hline Tricosanoic acid (C23:0) & $1.448 \pm 0.121$ & $0.604 \pm 0.123$ & 0.001 \\
\hline Nervonic acid (C24:1) & $0.222 \pm 0.085$ & $0.309 \pm 0.072$ & NS \\
\hline Lignoceric acid (C24:0) & $0.403 \pm 0.099$ & $0.205 \pm 0.069$ & NS \\
\hline Total SFA & $103.756 \pm 7.457$ & $59.554 \pm 5.834$ & 0.001 \\
\hline Total MUFA & $221.736 \pm 15.865$ & $92.279 \pm 11.202$ & $<0.001$ \\
\hline Total PUFA & $275.104 \pm 22.919$ & $87.434 \pm 8.559$ & $<0.001$ \\
\hline$(n-3) P U F A^{b}$ & $40.631 \pm 3.168$ & $26.852 \pm 2.653$ & 0.016 \\
\hline$(n-6) P U F A^{c}$ & $234.263 \pm 20.987$ & $60.504 \pm 7.733$ & $<0.001$ \\
\hline$(n-6):(n-3)$ PUFA ratio & $5.830 \pm 0.391$ & $2.437 \pm 0.326$ & $<0.001$ \\
\hline$\Delta^{9}$-desaturase $(16)^{\mathrm{d}}$ & $16.534 \pm 1.371$ & $9.380 \pm 0.870$ & $<0.001$ \\
\hline$\Delta^{9}$-desaturase $(18)^{\mathrm{e}}$ & $79.560 \pm 1.161$ & $72.843 \pm 0.842$ & $<0.001$ \\
\hline Elongase $^{f}$ & $82.693 \pm 0.683$ & $79.728 \pm 0.657$ & 0.012 \\
\hline
\end{tabular}

$P$ values are reported for differences between cows and heifers calculated using a general linear model taking animal type and stage as factors. SFAs, saturated fatty acids; MUFAs, monounsaturated fatty acids; PUFAs, polyunsaturated fatty acids.

${ }^{\mathrm{a} A n i m a l} \times$ stage interaction. ${ }^{\mathrm{b}}(\mathrm{n}-3) \mathrm{PUFA}=\Sigma(\mathrm{C} 18: 3 \mathrm{n} 3+\mathrm{C} 20: 5 \mathrm{n} 3+\mathrm{C} 20: 3 \mathrm{n} 3+\mathrm{C} 22: 6 \mathrm{n} 3) .{ }^{\mathrm{C}}(\mathrm{n}-6) \mathrm{PUFA}=\Sigma(\mathrm{C} 18: 3 \mathrm{n} 6+\mathrm{C} 18: 2 \mathrm{n} 6+\mathrm{C} 20: 4 \mathrm{n} 6+\mathrm{C} 20: 3 \mathrm{n} 6)$. ${ }^{\mathrm{d}} \Delta^{9}$-desaturase $(16)=$ index of desaturase enzyme activity in C16 fatty acids $100 \times\left(\frac{\mathrm{C} 16: 1}{\mathrm{C} 16: 1+\mathrm{C} 16: 0}\right)$. ${ }^{\mathrm{e}} \Delta^{9}$-desaturase $(18)=$ index of desaturase enzyme activity in $\mathrm{C} 18$ fatty acids $100 \times\left(\frac{\mathrm{C} 18: 1 \mathrm{n} 9}{\mathrm{C} 18: \ln 9+\mathrm{C} 18: 0}\right)$. ${ }^{\mathrm{f}}$ Elongase $=$ index of elongase enzyme activity in chain lengthening of $\mathrm{C} 16-\mathrm{C} 18$ fatty acids $100 \times\left(\frac{(\mathrm{C} 18: \ln 9+\mathrm{C} 18: 0)}{(\mathrm{C} 16: 1+\mathrm{C} 16: 0+\mathrm{C} 18: \ln 9+\mathrm{C} 18: 0)}\right)$.

significant animal $\times$ group interaction. The metabolites that were significantly different between cows and heifers included L-alanine, glycine, L-glutamine, urea, L-oxoproline, citric acid, inosine, maltose and lactose (Table 2). The stage effects are summarised in Table 3.

\section{Metabolomic analysis of serum samples from cows and heifers}

There was no effect of the stage of follicle development on insulin, insulin-like growth factor 1 (IGF1), glucose, NEFA and beta-hydroxybutyric acid (BHB) concentrations. However, lactating dairy cows had significantly lower insulin (6.37 vs $12.96 \mu \mathrm{lU} / \mathrm{ml})$, IGF1 (140.12 vs $482.02 \mathrm{ng} / \mathrm{ml}$ ) and glucose (3.50 vs $4.09 \mathrm{mmol} / \mathrm{l})$ concentrations and higher $\mathrm{BHB}(0.60$ vs $0.41 \mathrm{mmol} / \mathrm{l})$ concentrations than heifers on the day of tissue collection. For a subset of the animals $(n=8)$, serum samples were subjected to metabolomic analysis to ascertain the metabolite differences between the animals. In serum from cows, the fatty acids with the highest concentrations were linoleic acid, oleic acid, stearic acid and palmitic acid. In serum from heifers, the highest concentrations were found for oleic acid, stearic acid, linoleic acid and palmitic acid (see Table 4).

Analysis of differences between cows and heifers revealed that 11 organic compounds were significantly different. Serum samples from cows had significantly higher levels of nine organic compounds, namely myristic acid $(P=0.008), \gamma$-linolenic acid $(P=0.048)$, linoleic acid $(P<0.001)$, linolenic acid $(P=0.002)$, cis11 -eicosanoic acid $(P=0.007)$, dihomo- $\gamma$-linolenic acid $(P<0.001)$ and cis-eicosadienoic acid $(P=0.034)$. Heifers had significantly higher levels of docosahexaenoic acid (DHA; $P<0.001$; see Table 4).

From the quantitative data given in Tables 1 and 4 , it is clear that the fatty acid profile of the follicular fluid is 


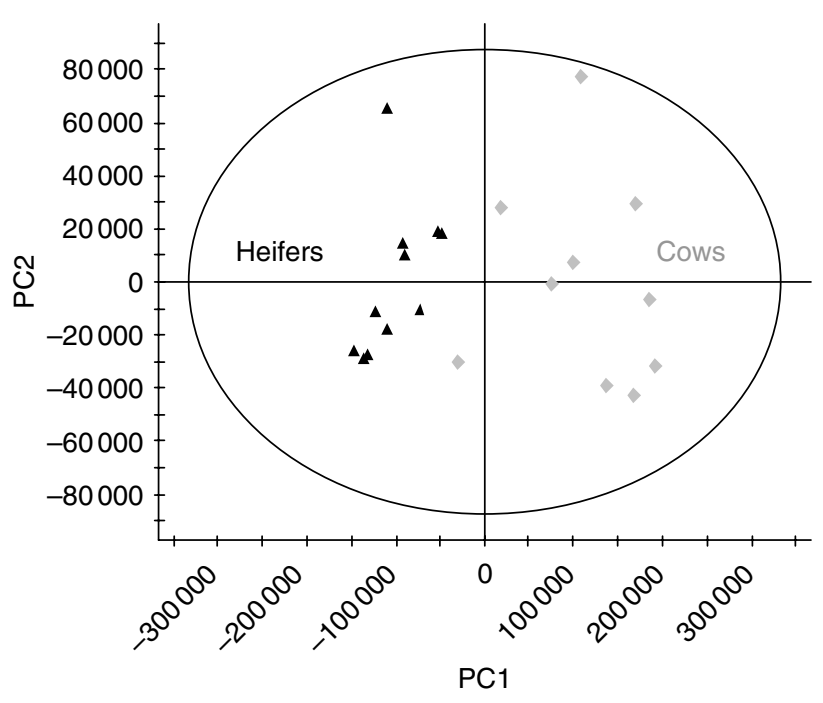

Figure 1 Principal component analysis (PCA) scores plot depicting principal component one (PC1) and principal component two (PC2) obtained from quantified fatty acids in follicular fluid from the dominant follicles of cows $(n=10)$ and heifers $(n=11)$.

different from that of serum for both cow and heifers. The most abundant fatty acids linoleic acid and oleic acid account for 37 and $35 \%$ of the total fatty acids in follicular fluid from cows, whereas in serum, they account for 25 and $17 \%$ respectively. Additionally, comparison of the fatty acids revealed significant differences between cows and heifers (Table 4). Moreover, comparison of this list with that obtained from analysis of the follicular fluid revealed that there were animal differences specific to the follicular fluid. These fatty acids include palmitoleic acid, palmitic acid, oleic acid, stearic acid and erucic acid.

\section{Analysis of follicular fluid from the dominant versus the subordinate follicles}

Follicular fluid from the subordinate follicle was significantly lower in 11 fatty acids, namely linolenic acid $(P=0.009)$, arachidonic acid $(P<0.001)$, eicosapentaenoic acid (EPA; $P=0.009$ ), cis-8,11, 4-eicosatrienoic acid $(P<0.001)$, eicosatrienoic acid (ETE; $P=0.005)$, cis-eicosadienoic acid $(P<0.001)$ and cis-11-eicosanoic acid $(P<0.001)$, compared with the dominant follicles. Also, the (n-3)PUFA fraction was significantly lower and elongase activity was significantly reduced compared with the dominant follicular fluid (see Table 5). Follicular fluid from the subordinate follicle was significantly higher in palmitoleic acid $(P=0.001)$ and palmitic acid $(P=0.027)$ compared with the dominant follicles (see Table 5). However, three of the fatty acids had a significant animal $\times$ follicle status interaction, which were palmitoleic acid, cis-eicosadienoic acid and cis-11-eicosanoic acid.

\section{Discussion}

The metabolite composition of follicular fluid was significantly different in cows compared with heifers, and between subordinate and dominant follicles. Detailed comparison with the serum fatty acid composition revealed that the follicular fluid has a unique lipid composition.

The dominant fatty acids present in follicular fluid were linoleic acid, oleic acid, stearic acid and palmitic acid in both cows and heifers. Significant differences were found between animals with higher levels of total SFA, MUFA and PUFA in follicular fluid from cows. Comparison of the fatty acid profile from serum with that from follicular fluid revealed that the composition of the follicular fluid is unique, and that it is not a simple reflection of differences in serum profiles. Follicular fluid obtains metabolites in part from serum and in part from local cells, meaning that the metabolic activity of follicular cells will have an impact on its composition. The follicular fluid compositional differences between cows and heifers reported here are not due to follicle size or oestradiol $\left(\mathrm{OE}_{2}\right)$ concentration differences. The current data support a hypothesis that the compositional changes reflect different metabolic activities of the follicular cells. Total SFA in follicular fluid was significantly higher in cows than in heifers, but this difference was not reflected in serum. More specifically, both palmitic acid and stearic acid were significantly higher in follicular fluid from cows compared with heifers, but were not significantly different in serum. Leroy et al. (2005) reported that the presence of increased palmitic acid during in vitro maturation had a negative effect on the rate of blastocyst formation. Additionally, palmitic acid and stearic acid were shown to have adverse effects on bovine granulosa cell in vitro growth and function (Vanholder et al. 2005), a phenomenon also found in human granulosa cells (Mu et al. 2001), possibly through the induction of

Table 2 Aqueous metabolites significantly different between follicular fluid from cows $(n=11)$ and heifers $(n=13)$. Values are mean \pm s.E.M.

\begin{tabular}{lccr}
\hline Metabolite & Cow & Heifer & $\boldsymbol{P}$ \\
\hline \multicolumn{4}{l}{ Quantified compounds $(\mu \mathrm{mol} / \mathrm{l})$} \\
L-alanine & $456.88 \pm 34.52$ & $800.88 \pm 45.89$ & $<0.001$ \\
Glycine & $782.11 \pm 37.69$ & $456.10 \pm 49.97$ & $<0.001$ \\
L-glutamine & $657.56 \pm 43.56$ & $313.56 \pm 32.15$ & $<0.001$ \\
Urea & $6429.22 \pm 975.74$ & $5839.98 \pm 826.41$ & 0.048 \\
Semi-quantified & \multicolumn{4}{c}{ compounds (relative units) } & \\
L-oxoproline & $96.82 \pm 13.11$ & $183.57 \pm 26.58$ & 0.002 \\
Citric acid & $1072.03 \pm 102.27$ & $722.90 \pm 67.26$ & 0.029 \\
Inosine & $8.67 \pm 4.39$ & $23.71 \pm 7.04$ & 0.019 \\
Maltose & $552.32 \pm 140.14$ & $131.43 \pm 68.94$ & 0.039 \\
Lactose & $13.12 \pm 3.18$ & $0.97 \pm 0.16$ & 0.001 \\
\hline
\end{tabular}

$P$ values are reported from general linear model analysis with animal type and stage as factors.

${ }^{\mathrm{a}}$ Animal $\times$ group interaction. 
Table 3 Aqueous metabolites significantly different between follicular fluid from group A (newly selected dominant follicle; $n=6$ ), B (preovulatory follicle prior to oestrus, $n=10$ ) and C (luteinised preovulatory follicle, $n=8$ ). Values are mean \pm s.E.M.

\begin{tabular}{|c|c|c|c|c|}
\hline Metabolite & A & B & $\mathrm{C}$ & $\boldsymbol{P}$ \\
\hline \multicolumn{5}{|c|}{ Quantified compounds ( $\mu \mathrm{mol} / \mathrm{l})$} \\
\hline $\begin{array}{l}\text { L-glutamine } \\
\text { L-lysine }\end{array}$ & $\begin{array}{c}544.68 \pm 103.44^{\mathrm{C}} \\
59.89 \pm 27.66^{\mathrm{C}}\end{array}$ & $\begin{array}{l}500.70 \pm 71.29 \\
202.23 \pm 44.51\end{array}$ & $\begin{array}{l}379.28 \pm 57.92 \\
299.00 \pm 43.64\end{array}$ & $\begin{array}{l}0.012 \\
0.019\end{array}$ \\
\hline Urea & $8332.70 \pm 931.69^{\mathrm{B}}$ & $3537.06 \pm 614.57^{C}$ & $7659.28 \pm 826.53$ & $<0.001$ \\
\hline Glucose & $3398.69 \pm 305.62^{\mathrm{B}, \mathrm{C}}$ & $6222.98 \pm 306.72$ & $6154.25 \pm 869.64$ & 0.010 \\
\hline \multicolumn{5}{|c|}{ Semi-quantified compounds (relative units) } \\
\hline Pyrimidine & $40.88 \pm 11.11^{\mathrm{B}}$ & $12.85 \pm 2.80$ & $20.16 \pm 6.56$ & 0.033 \\
\hline Galactose & $2453.90 \pm 278.04^{\mathrm{B}}$ & $5536.65 \pm 600.14$ & $4460.40 \pm 685.19$ & 0.009 \\
\hline Pantothenic acid & $7.73 \pm 2.25^{\mathrm{B}}$ & $4.64 \pm 0.83$ & $3.21 \pm 0.86$ & 0.028 \\
\hline Inosine & $49.99 \pm 5.01^{\mathrm{B}, \mathrm{C}}$ & $4.97 \pm 1.61$ & $6.73 \pm 4.99$ & $<0.001$ \\
\hline
\end{tabular}

$P$ values are reported from general linear model analysis with animal type and stage as factors. Superscript letters indicate the groups from which the values are significantly different.

apoptosis. Moreover, previous studies report that competent human oocytes generally have lower levels of SFAs (Haggarty et al. 2006). Comparison of the follicular fluid from the dominant and subordinate follicles showed that there was significantly less palmitic acid $(40 \%)$ associated with the dominant follicle in cows. This taken together with the compositional differences observed in the present study supports the hypothesis that high palmitic acid levels may have a negative impact on oocyte and embryo quality. Ultimately, the high levels of SFA in cows will lead to the accumulation of these lipids in the oocytes and embryos, and excessive lipid accumulation has been shown to impair embryo quality (Abe et al. 1999, Reis et al. 2003).

The total PUFA fraction and the percentage contribution of PUFA to the total fatty acid pool are significantly higher in follicular fluid from cows compared with heifers. Further examination of the PUFA content revealed that the n-6 PUFAs were dominant in terms of both the absolute concentration and their percentage contribution in cows, whereas the $\mathrm{n}-3$ PUFAs had a higher percentage contribution to the follicular fluid from heifers. In particular, DHA (C22:6n3) was significantly higher in follicular fluid and serum from heifers. Additionally, comparison of the follicular fluid from subordinate and dominant follicles revealed significant differences in the n-3 PUFAs. For the total fractions, there were significantly higher n-3 PUFAs in the dominant follicle of both animal types. The change in the n-3 PUFA fraction on going from subordinate to dominant was more dramatic for heifers with fivefold higher concentrations in the dominant follicle. This increase is due mainly to increases in linolenic acid, EPA and DHA. As a result of these increases, the $n 3: n 6$ ratios were dramatically reduced in heifer follicular fluid from dominant follicles. It is worth noting that the $\mathrm{n} 3: \mathrm{n} 6$ ratios in follicular fluid from subordinate follicles are similar in cows and heifers, and changes are only present in fluid from dominant follicles. A recent paper (Marei et al. 2009) showed that the n-3 PUFA linolenic acid influenced oocyte development. Treatment of bovine COCs with $50 \mu \mathrm{M}$ linolenic acid affected oocyte maturation leading to an increase in the number of MII stage oocytes. However, higher concentrations were detrimental, and these higher concentrations correspond to the levels found in follicular fluid from cows (average $120 \mu \mathrm{M})$. Considering this together with the quantitative differences reported here, it is possible to postulate that there is a concentration range in which n-3 PUFA levels exert beneficial effects. In recent years, there has been an increased interest in bovine n-3 PUFA supplementation studies with a focus on the potential effects on fertility (Bilby et al. 2006a, 2006b, 2006c). However, the results from such studies have been conflicting, with some reporting positive effects on fertilisation and embryo development (Cerri et al. 2009) and others reporting no effects (Robinson et al. 2002, Childs et al. 2008a, $2008 b$ ). The present study highlights that supplementation studies should take into consideration the chain length, degree of saturation and optimal final concentration. Moreover, it identifies the n3:n6 ratio and DHA as potential targets for future supplementation studies in dairy cows.

Analysis of the aqueous metabolites revealed that glycine and L-alanine are two of the most abundant amino acids in the bovine follicular fluid in agreement with a previous study (Sinclair et al. 2008). PCA did not show a separation between the metabolic profiles of follicular fluid from cows and heifers. However, focusing on the individual metabolites showed that there were a small number of differences. Among these differences were significantly higher levels of glycine and L-glutamine and lower levels of L-alanine and oxoproline in follicular fluid from cows compared with heifers. A previous study has demonstrated the predictive potential of glycine and L-alanine for developmental potential of oocytes, especially in oocytes of poorer quality (Sinclair et al. 2008). Addition of alanine and glycine into the culture media significantly enhanced bovine embryonic development and blastocyst cell number (Lee \& Fukui 
Table 4 Fatty acid composition of serum in cows $(n=4)$ and heifers $(n=4)$. Values are expressed as means $(\mu \mathrm{g} / \mathrm{ml}) \pm$ s.E.M.

\begin{tabular}{|c|c|c|c|}
\hline Fatty acid & Cow & Heifer & $\boldsymbol{P}$ \\
\hline Myristoleic acid (C14:1) & $0.299 \pm 0.234$ & $0.009 \pm 0.001$ & NS \\
\hline Myristic acid (C14:0) & $5.541 \pm 0.365$ & $3.831 \pm 0.251$ & 0.008 \\
\hline Pentadecenoic acid (C15:1) & $2.010 \pm 1.645$ & $0.412 \pm 0.382$ & NS \\
\hline Palmitoleic acid (C16:1) & $30.764 \pm 5.738$ & $16.371 \pm 2.949$ & NS \\
\hline Palmitic acid (C16:0) & $160.317 \pm 23.551$ & $123.153 \pm 8.203$ & NS \\
\hline Heptadecenoic acid (C17:1) & $8.775 \pm 0.802$ & $8.463 \pm 0.925$ & NS \\
\hline$\gamma$-Linolenic acid (C18:3n6) & $5.661 \pm 0.861$ & $2.585 \pm 0.897$ & 0.048 \\
\hline Linoleic acid (C18:2n6) & $573.913 \pm 33.312$ & $198.345 \pm 7.842$ & $<0.001$ \\
\hline Linolenic acid (C18:3n3) & $82.218 \pm 4.689$ & $49.151 \pm 4.175$ & 0.002 \\
\hline Oleic acid (C18:1n9c) & $402.440 \pm 59.561$ & $253.408 \pm 35.360$ & NS \\
\hline Stearic acid (C18:0) & $221.874 \pm 8.481$ & $198.555 \pm 17.362$ & NS \\
\hline Arachidonic acid (C20:4n6) & $20.707 \pm 6.089$ & $26.147 \pm 2.786$ & NS \\
\hline EPA $(C 20: 5 n 3)$ & $17.622 \pm 5.127$ & $29.742 \pm 2.327$ & NS \\
\hline DGLA (C20:3n6) & $21.815 \pm 4.423$ & $11.343 \pm 1.837$ & $<0.001$ \\
\hline cis-Eicosadienoic acid (C20:2) & $0.672 \pm 0.030$ & $0.515 \pm 0.049$ & 0.034 \\
\hline cis-11-Eicosanoic acid (C20:1) & $0.529 \pm 0.029$ & $0.325 \pm 0.042$ & 0.007 \\
\hline ETE $(C 20: 3 n 3)$ & $0.061 \pm 0.018$ & $0.034 \pm 0.010$ & NS \\
\hline Arachidic acid (C20:0) & $0.591 \pm 0.057$ & $0.706 \pm 0.120$ & NS \\
\hline Heneicosanoic acid (C21:0) & $0.014 \pm 0.004$ & $0.087 \pm 0.048$ & NS \\
\hline DHA (C22:6n3) & $1.425 \pm 0.205$ & $4.562 \pm 0.254$ & $<0.001$ \\
\hline Docosadienoic acid & $0.018 \pm 0.003$ & $0.024 \pm 0.005$ & NS \\
\hline Erucic acid (C22:1n9) & $0.039 \pm 0.008$ & $0.050 \pm 0.010$ & NS \\
\hline Behenic acid (C22:0) & $0.007 \pm 0.002$ & $0.010 \pm 0.004$ & NS \\
\hline Tricosanoic acid (C23:0) & $6.082 \pm 1.492$ & $0.659 \pm 0.643$ & 0.016 \\
\hline Nervonic acid (C24:1) & $0.002 \pm 0.001$ & $0.002 \pm 0.001$ & NS \\
\hline Lignoceric acid (C24:0) & $0.001 \pm 0.000$ & $0.001 \pm 0.000$ & NS \\
\hline Total SFA & $394.441 \pm 23.822$ & $327.012 \pm 25.777$ & NS \\
\hline Total MUFA & $444.859 \pm 67.339$ & $279.059 \pm 38.745$ & NS \\
\hline Total PUFA & $724.113 \pm 48.822$ & $322.446 \pm 16.888$ & $<0.001$ \\
\hline$(n-3) P U F A^{a}$ & $101.326 \pm 8.665$ & $83.488 \pm 5.426$ & NS \\
\hline$(n-6) P U F A^{b}$ & $622.097 \pm 41.660$ & $238.419 \pm 12.554$ & $<0.001$ \\
\hline$(n-6):(n-3)$ PUFA ratio & $6.189 \pm 0.330$ & $2.869 \pm 0.131$ & $<0.001$ \\
\hline$\Delta^{9}$-desaturase $(16)^{\mathrm{C}}$ & $15.855 \pm 1.127$ & $11.414 \pm 1.432$ & NS \\
\hline$\Delta^{9}$-desaturase $(18)^{\mathrm{d}}$ & $63.501 \pm 3.565$ & $55.608 \pm 2.000$ & NS \\
\hline Elongase $^{\mathrm{e}}$ & $76.831 \pm 1.159$ & $76.205 \pm 0.847$ & NS \\
\hline
\end{tabular}

$P$ values are reported for ANOVA. SFAs, saturated fatty acids; MUFAs, monounsaturated fatty acids; PUFAs, polyunsaturated fatty acids.

${ }^{\mathrm{a}}(\mathrm{n}-3) \mathrm{PUFA}=\Sigma(\mathrm{C} 18: 3 \mathrm{n} 3+\mathrm{C} 20: 5 \mathrm{n} 3+\mathrm{C} 20: 3 \mathrm{n} 3+\mathrm{C} 22: 6 \mathrm{n} 3) .{ }^{\mathrm{b}}(\mathrm{n}-6) \mathrm{PUFA}=\Sigma(\mathrm{C} 18: 3 \mathrm{n} 6+\mathrm{C} 18: 2 \mathrm{n} 6+\mathrm{C} 20: 4 \mathrm{n} 6+\mathrm{C} 20: 3 \mathrm{n} 6) .{ }^{\mathrm{c}} \Delta^{9}-\mathrm{des}$ aturase $(16)=$ index of desaturase enzyme activity in C16 fatty acids $100 \times\left(\frac{\mathrm{C} 16: 1}{\mathrm{C} 16: 1+\mathrm{C} 16: 0}\right) .{ }^{\mathrm{d}} \Delta^{9}$-desaturase $(18)=$ index of desaturase enzyme activity in C18 fatty acids $100 \times\left(\frac{\mathrm{C} 18: 1 \mathrm{n} 9}{\mathrm{C} 18: 1 \mathrm{n} 9+\mathrm{C} 18: 0}\right) .{ }^{\text {e}}$ Elongase $=$ index of elongase enzyme activity in chain lengthening of $\mathrm{C} 16-\mathrm{C} 18 \mathrm{fatty}$ acids $100 \times\left(\frac{(\mathrm{C} 18: 1 \mathrm{n} 9+\mathrm{C} 18: 0)}{(\mathrm{C} 16: 1+\mathrm{C} 16: 0+\mathrm{C} 18: 1 \mathrm{n} 9+\mathrm{C} 18: 0)}\right)$.

1996). In denuded oocytes which cannot use cumulus cells for supply of oxidative substrates, addition of alanine resulted in increased meiotic maturation (Cetica et al. 2007). Although little is known about the influence of L-glutamine on oocyte quality, studies have shown that it has positive effects on embryo viability (Gardner \& Lane 1993, Steeves \& Gardner 1999). In addition to changes in amino acid levels, comparison of the aqueous metabolites revealed changes in citric acid. Citric acid is an intermediate in the TCA cycle, and its higher concentrations in cow follicular fluid may be reflective of an increased dependence on oxidative metabolism in cows.

The global metabolic profile did not change with the stage of follicle development. However, a small number of amino acids and carbohydrates changed significantly. Included in these changes were L-glutamine, lysine and glucose. Lysine levels were higher in groups B and C. Previous studies have shown that lysine changes with the stages of the oestrous cycle (Orsi et al. 2005). Studies in pigs have demonstrated that low lysine intake impaired follicle development and reduced the ability of follicles to support oocyte maturation (Yang et al. 2000). Glucose levels increased in groups B and C, which may be reflective of a decreased uptake of glucose as follicle differentiation occurs.

\section{Conclusion}

In conclusion, the present study demonstrates that follicular fluid fatty acid concentrations do not directly reflect serum concentrations. In addition, follicular fluid from cows contains higher levels of SFAs, which can be detrimental for oocyte maturation and early embryo development. Overall, the data presented here support a hypothesis that the follicle microenvironment in cows places their oocytes at a developmental disadvantage compared with heifers, and that this may contribute to the well-characterised differences in fertility. 
Table 5 Comparison of fatty acid composition of follicular fluid from dominant and subordinate follicles ( $n=5$ per group) in cow and heifers. Values are expressed as means $(\mu \mathrm{g} / \mathrm{ml}) \pm$ S.E.M.

\begin{tabular}{|c|c|c|c|c|c|}
\hline \multirow[b]{2}{*}{ Fatty acid } & \multicolumn{2}{|c|}{ Dominant follicle } & \multicolumn{2}{|c|}{ Subordinate follicle } & \multirow[b]{2}{*}{$\boldsymbol{P}$} \\
\hline & Cow & Heifer & Cow & Heifer & \\
\hline Palmitoleic acid (C16:1) ${ }^{\mathrm{a}}$ & $11.149 \pm 0.872$ & $3.899 \pm 0.968$ & $23.738 \pm 0.264$ & $5.252 \pm 1.189$ & 0.001 \\
\hline Palmitic acid (C16:0) & $49.699 \pm 6.836$ & $30.471 \pm 5.092$ & $82.990 \pm 9.107$ & $34.785 \pm 5.504$ & 0.027 \\
\hline Linolenic acid (C18:3n3) & $24.727 \pm 3.206$ & $19.579 \pm 3.408$ & $17.994 \pm 1.892$ & $4.317 \pm 2.055$ & 0.009 \\
\hline Arachidonic acid (C20:4n6) & $10.489 \pm 0.648$ & $10.960 \pm 1.858$ & $0.032 \pm 0.005$ & $0.0294 \pm 0.007$ & $<0.001$ \\
\hline EPA (C20:5n3) & $10.962 \pm 0.050$ & $12.997 \pm 3.297$ & $4.089 \pm 0.404$ & $0.0241 \pm 0.004$ & 0.009 \\
\hline DGLA (C20:3n6) & $4.389 \pm 0.028$ & $3.568 \pm 0.638$ & $0.317 \pm 0.299$ & $0.059 \pm 0.043$ & $<0.001$ \\
\hline cis-Eicosadienoic acid (C20:2) & $0.302 \pm 0.036$ & $0.037 \pm 0.015$ & $0.071 \pm 0.017$ & $0.014 \pm 0.002$ & $<0.001$ \\
\hline cis-11-Eicosanoic acid $(C 20: 1)^{a}$ & $0.315 \pm 0.058$ & $0.025 \pm 0.005$ & $0.016 \pm 0.006$ & $0.0166 \pm 0.002$ & $<0.001$ \\
\hline ETE (C20:3n3) & $0.007 \pm 0.001$ & $0.0131 \pm 0.004$ & $0.079 \pm 0.015$ & $0.087 \pm 0.024$ & 0.005 \\
\hline Arachidic acid (C20:0) & $0.140 \pm 0.012$ & $0.093 \pm 0.043$ & $0.019 \pm 0.007$ & $0.027 \pm 0.012$ & 0.020 \\
\hline Heneicosanoic acid (C21:0) & $0.007 \pm 0.002$ & $0.007 \pm 0.001$ & $0.003 \pm 0.001$ & $0.004 \pm 0.001$ & 0.038 \\
\hline Erucic acid (C22:1n9) & $0.158 \pm 0.004$ & $0.032 \pm 0.021$ & $0.0439 \pm 0.037$ & $0.004 \pm 0.002$ & 0.011 \\
\hline Behenic acid (C22:0) & $0.254 \pm 0.099$ & $0.123 \pm 0.055$ & $0.010 \pm 0.005$ & $0.005 \pm 0.001$ & 0.013 \\
\hline Tricosanoic acid (C23:0) & $1.265 \pm 0.250$ & $0.786 \pm 0.407$ & $0.006 \pm 0.003$ & $0.015 \pm 0.007$ & 0.011 \\
\hline Lignoceric acid (C24:0) & $0.543 \pm 0.223$ & $0.394 \pm 0.217$ & $0.001 \pm 0.000$ & $0.001 \pm 0.000$ & 0.028 \\
\hline$(n-3) P U F A^{b}$ & $36.214 \pm 3.394$ & $33.702 \pm 6.988$ & $22.292 \pm 5.911$ & $4.599 \pm 1.982$ & 0.035 \\
\hline$(n-6):(n-3) P^{\prime} U_{F}{ }^{c}$ & $4.584 \pm 0.154$ & $1.992 \pm 0.789$ & $8.334 \pm 3.016$ & $11.037 \pm 3.128$ & 0.035 \\
\hline Elongase $^{\mathrm{d}}$ & $81.284 \pm 1.074$ & $80.926 \pm 0.330$ & $73.935 \pm 1.923$ & $68.989 \pm 1.166$ & $<0.001$ \\
\hline
\end{tabular}

$P$ values are reported for dominant follicle versus subordinate follicle comparisons taking animal and follicle type as factors.

${ }^{\mathrm{a}}$ Animal $\times$ follicle interaction; $P<0.05 .{ }^{\mathrm{b}}(\mathrm{n}-3) \mathrm{PUFA}=\Sigma(\mathrm{C} 18: 3 \mathrm{n} 3+\mathrm{C} 20: 5 \mathrm{n} 3+\mathrm{C} 20: 3 \mathrm{n} 3+\mathrm{C} 22: 6 \mathrm{n} 3) .{ }^{\mathrm{C}}(\mathrm{n}-6) \mathrm{PUFA}=\Sigma(\mathrm{C} 18: 3 \mathrm{n} 6+\mathrm{C} 18: 2 \mathrm{n} 6+$

$\mathrm{C} 20: 4 \mathrm{n} 6+\mathrm{C} 20: 3 \mathrm{n} 6) .{ }^{\mathrm{d}}$ Elongase $=$ index of elongase enzyme activity in chain lengthening of $\mathrm{C} 16-\mathrm{C} 18$ fatty acids $100 \times\left(\frac{(\mathrm{C} 18: 1 \mathrm{n} 9+\mathrm{C} 18: 0)}{(\mathrm{C} 16: 1+\mathrm{C} 16: 0+\mathrm{C} 18: 1 \mathrm{n} 9+\mathrm{C} 18: 0)}\right)$.

\section{Materials and Methods}

\section{Animals and tissue preparation}

All experimental procedures involving animals were licensed by the Department of Health and Children, Ireland, in accordance with the cruelty to animals act (Ireland 1897) and European Community Directive 86/609/EC. In addition, this experiment was approved by the University's Animal Research Ethics Committee. All animals were maintained at Lyons Research Farm in Ireland on a permanent grassland site consisting of $>80 \%$ perennial ryegrass. Cows were milked at 0700 and $1600 \mathrm{~h}$ daily, and concentrates $(2 \mathrm{~kg})$ were offered on a flat-rate basis in individual stalls twice daily in a 20-unit sideby-side herringbone milking parlour. The mean days in milk until tissue collection were $80.9 \pm 2.98$. The oestrous cycles of Holstein-Friesian dairy cows $(n=13$; mean lactation number 3.75) and 15 Holstein-Friesian heifers (1.6 years) were synchronised. Day 0 was defined as the day of observed oestrus. Oestrus for both groups was defined as the period when the animal stood to be mounted by another animal. On day 8 (after observed oestrus), a used CIDR (containing $1.38 \mathrm{~g}$ of progesterone, CIDR; Pfizer Pharma $\mathrm{GmbH}$, Karlsruhe, Germany) was inserted intravaginally in both multiparous and nulliparous animals, and ovarian follicle development was monitored by transrectal ultrasonography (Aloka SSD-900 linear array transrectal probe, $7.5-\mathrm{MHz}$ transducer; BCF Ireland Ltd, Fermoy, Ireland). Furthermore, diagrams of the follicles, their diameters and their respective positions on the ovary were noted on each day of scanning.

On day 14 , the used CIDRs were removed from animals in group A (newly selected dominant follicle in the luteal phase, $n=8$ ), and they were slaughtered. The remaining animals received a luteolytic dose of prostaglandin (Estrumate,
Chanelle, Loughrea, Co. Galway, Ireland) on day 13, and the CIDRs were removed 2 days later. Animals in group B (preovulatory follicle prior to oestrus, $n=11$ ) were slaughtered on day 16 between 24 and $30 \mathrm{~h}$ after CIDR removal. Animals in group C (luteinised preovulatory follicle, $n=9$ ) received an i.m. injection of $5 \mathrm{ml}$ GNRH (0.02 mg buserelin; Receptal; Chanelle) on day $16 \sim 30 \mathrm{~h}$ after CIDR removal, and were slaughtered between 18 and $22 \mathrm{~h}$ after GNRH injection.

Following slaughter, each pair of ovaries from the same animal was removed and placed in ice-cold PBS. Identification of dominant and subordinate follicles was aided by ovarian diagrams as recorded between day 8 and day of slaughter of each animal. The external diameter of each follicle was measured using callipers, and follicular fluid was aspirated from both the dominant and the largest subordinate follicles, snap frozen in liquid nitrogen and stored at $-80^{\circ} \mathrm{C}$. Progesterone and $\mathrm{OE}_{2}$ assays were performed on the follicular fluid to ensure the correct classification of the dominant follicle for each animal. The dominant follicle was identified as being larger and containing more $\mathrm{OE}_{2}$ than other follicles. Blood samples were collected by jugular venipuncture from each animal on the day of the slaughter, and were refrigerated $\left(4^{\circ} \mathrm{C}\right)$ for $12-24 \mathrm{~h}$ before being centrifuged for $20 \mathrm{~min}$ at $2000 \mathrm{~g}$ at $4{ }^{\circ} \mathrm{C}$. Serum was separated and stored at $-20^{\circ} \mathrm{C}$.

\section{Metabolite extraction and analysis}

Follicular fluid samples were thawed on ice prior to analysis. Aqueous compounds were isolated using a methanolic extraction (Jiye et al. 2008) following deproteinisation with acetonitrile. Briefly, $200 \mu \mathrm{l}$ of deproteinised sample were combined with $20 \mu \mathrm{l}$ of ${ }^{13} \mathrm{C}$ myristic acid (Cambridge Isotopes, Andover, MA, USA) as an internal standard prior to extraction 
with $800 \mu \mathrm{l}$ methanol. Extracts were dried, and samples were methoximised using $30 \mu \mathrm{l}$ of methoxamine $(20 \mathrm{mg} / \mathrm{ml}$ in pyridine) for $17 \mathrm{~h}$ at room temperature prior to silation with $30 \mu$ of $N$-trimethylsilyl-N-methyl trifluoroacetamide + trimethoxyflavone for $1 \mathrm{~h}$. Samples were diluted with $240 \mu \mathrm{l}$ of hexane prior to analysis by gas chromatography mass spectrometry (GC-MS). One microlitre of sample was injected in splitless mode using an Agilent 7890A GC coupled with a $5975 \mathrm{C} \mathrm{MS}$. The temperature of the injector was maintained at $220^{\circ} \mathrm{C}$, with an initial oven temperature at $70{ }^{\circ} \mathrm{C}$ which was increased to $320^{\circ} \mathrm{C}$ at $5{ }^{\circ} \mathrm{C} / \mathrm{min}$. The transfer line temperature was $250^{\circ} \mathrm{C}$. Helium was used as the carrier gas with a column flow of $1.2 \mathrm{ml} / \mathrm{min}$ over an Agilent HP-5ms $30 \mathrm{~m} \times 250 \mu \mathrm{m} \times$ $0.25 \mu \mathrm{m}$ column. The $5975 \mathrm{C}$ MS was operated in scan mode acquiring data from 30 to $550 \mathrm{~m} / z$. Compound identification and calibration were achieved by referencing to in-house standards using Agilent Chemstation MSD E.02.00.493, and by comparison of their mass spectra with those in the National Institute of Standards and Technology (NIST) Library 2.0 (2005).

For the analysis of organic compounds, $300 \mu \mathrm{l}$ of follicular fluid or serum were combined with $20 \mu \mathrm{l}$ of $2 \mathrm{mg} / \mathrm{ml}$ pentadecanoic acid (C15:0) as an internal standard, and extracted using a 1:2 mixture of chloroform:methanol based on the method of Bligh \& Dyer (1959). Extracts were derivatised by methylation using methanolic $\mathrm{BF}_{3}$. Derivatives were re-suspended in $200 \mu \mathrm{l}$ of hexane and analysed on an Agilent 7890A GC coupled with a 5975C MS with an Agilent HP-5ms $30 \mathrm{~m} \times 250 \mu \mathrm{m} \times 0.25 \mu \mathrm{m}$ column. One microlitre of the sample was injected in splitless mode, and the initial oven temperature of $70^{\circ} \mathrm{C}$ was raised to $220^{\circ} \mathrm{C}$ at $5{ }^{\circ} \mathrm{C} / \mathrm{min}$, held for $20 \mathrm{~min}$, and then raised to $320^{\circ} \mathrm{C}$ at $20^{\circ} \mathrm{C} / \mathrm{min}$. Helium was used as the carrier gas with a flow of $1.2 \mathrm{ml} / \mathrm{min}$. Calibration was achieved by comparison of peak areas for fatty acids with reference to a known standard (Supelco 37 compound mix, Supelco, Poole, UK) using Agilent Chemstation MSD E.02.00.493., and by comparison of their mass spectra with those in the NIST Library 2.0 (2005). For quality control purposes, two aliquots from a pool of follicular fluid were extracted and analysed in parallel with each batch of samples.

Automatic peak detection was carried out with Agilent Chemstation MSD. Mass spectra deconvolution was performed with AMDIS version 2.65. Peaks with a signal-to-noise ratio $(\mathrm{S} / \mathrm{N})$ lower than 30 were rejected. To obtain accurate peak areas for the internal standard and specific peaks/compounds, one quant mass for each peak was specified as target, and three masses were selected as qualifiers. Each data file was manually analysed for false positives/negatives in Agilent Chemstation.

Both aqueous and organic datasets were divided into compounds identified and quantified using external standards and compounds semi-quantified relative to the internal standard only. Concentrations given for fatty acids are $\mu \mathrm{g} / \mathrm{ml} \pm$ S.E.M. Total SFA fraction, total MUFA fractions and total PUFA fractions, indices of desaturase enzyme activity in C16 fatty acids $\left(\Delta^{9}\right.$-desat (16)) and in C18 fatty acids ( $\Delta^{9}$-desat (18)), and elongase enzyme activity in chain lengthening of C16-C18 fatty acids were calculated using previously published equations (Malau-Aduli et al. 1998).
Plasma IGF1 concentrations were determined using a validated double-antibody RIA after ethanol-acetone-acetic acid extraction. Plasma insulin concentrations were determined using a solid-phase fluoroimmunoassay (AutoDELFIA; PerkinElmer Life and Analytical Science, Turku, Finland). Plasma glucose, NEFA and BHB concentrations were determined by enzymatic analysis using Randox imola system (Randox Laboratories Ltd, Co., Antrim, UK).

\section{Statistical analysis}

PCA and partial least squares discriminant analysis (PLS-DA) were performed on both datasets using SIMCA-P +11 (Umetrics, Crewe, UK). The quality of the models formed by PCA and PLS-DA was investigated by interrogation of the $R^{2}$ and $Q^{2}$ parameters. The $R^{2}$ parameter is a representation of how much of the variation within the dataset is explained by the components of the model. The $Q^{2}$ parameter gives an indication of how good the model is at class prediction. Correlation analysis, general linear model analysis and post hoc Bonferroni's test were performed using SPSS 14 (SPSS Inc., Chicago, IL, USA). Analysis of blood glucose, NEFA, insulin, IGF1 and BHB was performed by natural logarithm transformation and by analysis using mixed models. Significance was assumed when $P<0.05$.

\section{Supplementary data}

This is linked to the online version of the paper at http://dx.doi. org/10.1530/REP-10-0068.

\section{Declaration of interest}

The authors declare that there is no conflict of interest that could be perceived as prejudicing the impartiality of the research reported.

\section{Funding}

This work was supported by an SFI grant to the Reproductive Biology Research Cluster.

\section{References}

Abe H, Yamashita S, Itoh T, Satoh T \& Hoshi H 1999 Ultrastructure of bovine embryos developed from in vitro-matured and -fertilized oocytes: comparative morphological evaluation of embryos cultured either in serum-free medium or in serum-supplemented medium. Molecular Reproduction and Development 53 325-335.

Baka S \& Malamitsi-Puchner A 2006 Novel follicular fluid factors influencing oocyte developmental potential in IVF: a review. Reproductive Biomedicine Online 12 500-506.

Bilby TR, Sozzi A, Lopez MM, Silvestre FT, Ealy AD, Staples CR \& Thatcher WW 2006a Pregnancy, bovine somatotropin, and dietary n-3 fatty acids in lactating dairy cows: I. Ovarian, conceptus, and growth hormone-insulin-like growth factor system responses. Journal of Dairy Science 89 3360-3374.

Bilby TR, Guzeloglu A, MacLaren LA, Staples CR \& Thatcher WW $2006 b$ Pregnancy, bovine somatotropin, and dietary $n-3$ fatty acids in lactating dairy cows: II. Endometrial gene expression related to maintenance of pregnancy. Journal of Dairy Science 89 3375-3385. 
Bilby TR, Jenkins T, Staples CR \& Thatcher WW 2006c Pregnancy, bovine somatotropin, and dietary n-3 fatty acids in lactating dairy cows: III. Fatty acid distribution. Journal of Dairy Science 89 3386-3399.

Bligh EG \& Dyer WJ 1959 A rapid method of total lipid extraction and purification. Canadian Journal of Biochemistry and Physiology 37 911-917.

Booth PJ, Humpherson PG, Watson TJ \& Leese HJ 2005 Amino acid depletion and appearance during porcine preimplantation embryo development in vitro. Reproduction 130 655-668.

Butler WR 2000 Nutritional interactions with reproductive performance in dairy cattle. Animal Reproduction Science 2 449-457.

Cerri RL, Juche SO, Chebel RC, Rutiglian HM, Bruno RG, Galvão KN, Thatcher WW \& Santos JE 2009 Effect of fat source differing in fatty acid profile on metabolic parameters, fertilization, and embryo quality in high-producing dairy cows. Journal of Dairy Science 92 $1520-1531$.

Cetica P, Pintos L, Dalvit G \& Beconi M 2007 Involvement of enzymes of amino acid metabolism and tricarboxylic acid cycle in bovine oocyte maturation in vitro. Reproduction 126 753-763.

Childs S, Lynch CO, Hennessy AA, Stanton C, Wathes DC, Sreenan JM, Diskin MG \& Kenny DA 2008a Effect of dietary enrichment with either $\mathrm{n}-3$ or $\mathrm{n}-6$ fatty acids on systemic metabolite and hormone concentration and ovarian function in cattle. Animal 2 883-893.

Childs S, Hennessy AA, Sreenan JM, Wathes DC, Cheng Z, Stanton C, Diskin MG \& Kenny DA $2008 b$ Effect of level of dietary n-3 polyunsaturated fatty acid supplementation on systemic and tissue fatty acid concentrations on selected reproductive variables in cattle. Theriogenology 70 595-611.

Espey LL \& Lipner H 1994 Ovulation. In The Physiology of Reproduction, edn 2, pp 725-780. Eds E Knobil \& JD Neill. New York, NY: Raven Press.

Foote RH 1996 Review: dairy cattle reproductive physiology research and management-past progress and future prospects. Journal of Dairy Science 50 225-232.

Fortune JE 1994 Ovarian follicular growth and development in mammals. Biology of Reproduction 50 225-232.

Gardner DK \& Lane M 1993 Amino acids and ammonium regulate mouse embryo development in culture. Biology of Reproduction 48 377-385.

Gosden RG, Hunter RH, Telfer E, Torrance C \& Brown N 1988 Physiological factors underlying the formation of ovarian follicular fluid. Journal of Reproduction and Fertility 82 813-825.

Haggarty P, Wood M, Ferguson E, Hoad G, Srikantharajah A, Milne E, Hamilton M \& Bhattacharya S 2006 Fatty acid metabolism in human preimplantation embryos. Human Reproduction 21 766-773.

Hong J \& Lee E 2007 Intrafollicular amino acid concentration and the effect of amino acids in a defined maturation medium on porcine oocyte maturation, fertilization, and preimplantation development. Theriogenology 68 728-735.

Jiye A, Huang Q, Wang G, Zha W, Yan B, Ren H, Gu S, Zhang Y, Zhang Q, Shao $\mathbf{F}$ et al. 2008 Global analysis of metabolites in rat and human urine based on gas chromatography/time-of-flight mass spectrometry. Analytical Biochemistry 379 20-26.

Kell DB 2005 Metabolomics, machine learning and modelling: towards an understanding of the language of cells. Biochemical Society Transactions 33 520-524.

Lee ES \& Fukui Y 1996 Synergistic effect of alanine and glycine on bovine embryos cultured in a chemically defined medium and amino acid uptake by vitro-produced bovine morulae and blastocysts. Biology of Reproduction 55 1383-1389.

Leroy JL, Vanholder T, Delanghe JR, Opsomer G, Van Soom AV, Bols P, Dewulf J \& de Kruif A 2004a Metabolic changes in follicular fluid of the dominant follicle in high-yielding dairy cows early post partum. Theriogenology 62 1131-1143.

Leroy JL, Vanholder T, Delanghe JR, Opsomer G, Van Soom AV, Bols PEJ \& de Kruif A 2004b Metabolite and ionic composition of follicular fluid from different-sized follicles and their relationship to serum concentrations in dairy cows. Animal Reproduction Science 80 201-211.

Leroy JL, Vanholder T, Mateusen B, Christophe A, Opsomer G, de Kruif A, Genicot G \& Van Soom AV 2005 Non-esterified fatty acids in follicular fluid of dairy cows and their effect on developmental capacity of bovine oocytes in vitro. Reproduction 130 485-495.
Li R, Wen L, Wang S \& Bou S 2006 Development, freezability and amino acid consumption of bovine embryos cultured in synthetic oviductal fluid (SOF) medium containing amino acids at oviductal or uterine-fluid concentrations. Theriogenology 66 404-414.

Lopez-Gatius F 2002 Is fertility declining in dairy cattle? A retrospective study in northeastern Spain Theriogenology 60 89-99.

Malau-Aduli AE, Siebert BD, Bottema CD \& Pitchford WS 1998 Breed comparison of the fatty acid composition of muscle phospholipids in Jersey and Limousin cattle. Journal of Animal Science 76 766-773.

Marei WF, Wathes DC \& Fouladi-Nashta AA 2009 The effect of linolenic acid on bovine oocyte maturation and development. Biology of Reproduction 81 1064-1072.

McNatty KP 1978 Cyclic changes in antral fluid hormone concentrations in humans. Journal of Clinical Endocrinology and Metabolism 7 577-600.

Mu YM, Yanase T, Nishi Y, Tanaka A, Saito M, Jin CH, Mukasa C, Okabe T, Nomura M, Goto K et al. 2001 Saturated FFAs, palmitic acid and stearic acid, induce apoptosis in human granulosa cells. Endocrinology 142 3590-3597.

Orsi NM, Gopichandran N, Leese HJ, Picton HM \& Harris SE 2005 Fluctuations in bovine ovarian follicular fluid composition throughout the oestrous cycle. Reproduction 129 219-228.

Preis KA, Seidel GJ \& Gardner DK 2005 Metabolic markers of developmental competence for in vitro-matured mouse oocytes. Reproduction 130 475-483.

Reis A, Rooke JA, McCallum GJ, Staines ME, Ewen MA, Lomax M \& McEvoy TG 2003 Consequences of exposure to serum, with or without vitamin $\mathrm{E}$ supplementation, in terms of the fatty acid content and viability of bovine blastocysts produced in vitro. Reproduction, Fertility, and Development 15 275-284.

Renaville B, Bacciu N, Comin A, Motta M, Poli I, Vanini G \& Prandi A 2008 Plasma and follicular fluid fatty acid profiles in dairy cows. Reproduction in Domestic Animals 45 118-121.

Revelli A, Delle Piane L, Casano S, Molinari E, Massobrio M \& Rinaudo P 2009 Follicular fluid content and oocyte quality: from single biochemical markers to metabolomics. Reproductive Biology and Endocrinology $\mathbf{4}$ 7-40.

Robinson RS, Pushpakumara PG, Cheng Z, Peters AR, Abayasekara DR \& Wathes DC 2002 Effects of dietary polyunsaturated fatty acids on ovarian and uterine function in lactating dairy cows. Reproduction $\mathbf{1 2 4}$ 119-131.

Sinclair KD, Lunn LA, Kwong WY, Wonnacott K, Linforth RS \& Craigon J 2008 Amino acid and fatty acid composition of follicular fluid as predictors of in vitro embryo development. Reproductive Biomedicine Online 16 859-868.

Singh R \& Sinclair KD 2007 Metabolomics: approaches to assessing oocyte and embryo quality. Theriogenology 68 56-62.

Sirard MA, Richard F, Blondin P \& Robert C 2006 Contribution of the oocyte to embryo quality. Theriogenology 65 126-136.

Steeves TE \& Gardner DK 1999 Temporal and differential effects of amino acids on bovine embryo development in culture. Biology of Reproduction 61 731-740.

Vanholder T, Leroy JL, Soom AV, Opsomer G, Maes D, Coryn M \& de Kruif A 2005 Effect of non-esterified fatty acids on bovine granulosa cell steroidogenesis and proliferation in vitro. Animal Reproduction Science 87 33-44.

Yang H, Foxcroft GR, Pettigrew JE, Johnston LJ, Shurson GC, Costa AN \& Zak LJ 2000 Impact of dietary lysine intake during lactation on follicular development and oocyte maturation after weaning in primiparous sows. Journal of Animal Science 78 993-1000.

Zeron Y, Ocheretny A, Kedar O, Borochov A, Sklan D \& Arav A 2001 Seasonal changes in bovine fertility: relation to developmental competence of oocytes, membrane properties and fatty acid composition of follicles. Reproduction 121 447-454.

Received 3 February 2010

First decision 2 March 2010

Revised manuscript received 6 April 2010

Accepted 12 April 2010 